\title{
Comparative Reliability Analysis for Resonant Converter Operation under Component Ageing
}

\author{
Dorin O. Neacșu, Senior Member IEEE, Marcian Cirstea, Senior Member IEEE, \\ and Dan Butnicu, Member
}

\begin{abstract}
This paper is concerned with reliability analysis in relation to optimal switching of resonant power converters, aimed at minimizing their power loss and operational temperature and thus reducing their lifetime degradation. In most cases, high performance resonant converter control requires a continuous adaptation of the power device switching instances depending on the power input source, load current, or parameter variation in passive components. If the resonant converter is switched before or after the resonant swing ends, more loss is added to the system, with effects in operating temperature rise and reliability deterioration. Even if the switching frequency is adjusted to keep the output voltage constant, it may influence the operational temperature. This article is quantifying this problem with a calculation of the lifetime implication for both cases of Zero Voltage Transition (ZVT) and Zero Current Transition (ZCT) buck converters. A broad range of parameter variation in passive components is considered due to ageing or aggravated stress. A thorough performance (lifetime / reliability) evaluation is achieved through a comparative analysis of results obtained for resonant converters with ideal operation, resonant converters with adjusted timing due to parameter variation, and hard-switched converters without any resonance. Conclusions are formulated in the end. The results reported in the paper should be of high interests to the power electronics community, given that resonant converters are used in a wide range of applications due to their ability to reduce power semiconductor losses.
\end{abstract}

Index Terms-reliability, thermal stress, computer aided analysis, buck converter, resonant converter

\section{INTRODUCTION}

A contemporary paradigm shift takes place within technological evolution of power electronics leading towards re-established and more demanding performance criteria. Meeting newer performance demands for power converters implies a considerable amount of research for reliability, lifetime, and failure rate calculation, recently reported either as review materials [1-4], or case studies [512]. The first category aims to increase awareness about the topic, while the latter group provides samples of deeper analysis. This effort is governed by a set of dedicated standards [13-15] introduced and used by the power electronics industry for component lifetime calculation.

Manuscript received May 02, 2020; revised July 17, 2020 and October 2020; accepted December 1, 2020.

Dorin O. Neacşu and Dan Butnicu are with the Technical University of Iași, Iași, Romania (e-mail: dorin.neacsu@ieee.org, dbutnicu@etti.tuiasi.ro).

Marcian Cirstea is with the Anglia Ruskin University, Cambridge, UK (email: marcian.cirstea@anglia.ac.uk).
Additional to the calculation itself, contemporary research is also dedicated to improving component technologies in respect to lifetime and reliability [16-26].

It is therefore timely to investigate the lifetime for converters operated under special modes, as it is the case with resonant converters. They constitute a technology derivative from the previous paradigm of efficiency improvement through semiconductor loss reduction. Since the power loss in transistors depends on both instantaneous voltage and current, resonant converters try to keep one of them at zero during the switching instants by adding resonant circuits near power semiconductor transistors. A reduction of power semiconductors loss yields and the power semiconductors are operated at a lower temperature. When the saved power loss is larger than the inherent loss in the newly-added components and control, the overall efficiency also improves. The designer aims to solve a tradeoff between the added cost of an additional resonant circuit and its appropriate advanced control method, versus the reduction in temperature and potential system efficiency improvement.

However, the research meeting the efficiency improvement paradigm mostly neglected a comprehensive study of the possible adverse effects or limitations when using resonant converters. This article comes in to investigate reliabilityrelated effects of a parameter variation. Since the timing involved in the operation of the resonant converter depends on the initial design dataset, a variation in parameters of the passive components building up the resonant circuit may lose the main feature of efficiency improvement along a deterioration of reliability figure.

This study is fueled by an impressive number of recent papers [16-26] dedicated to the study of ageing and aftershock variation of capacitance and inductance manufactured by using a variety of technologies for passive components. Without considering the specifics of a certain technology in particular, this article studies the total effects of parameter variation.

Conventional resonant buck converters are considered herein as a case study, and conclusions are depicted for both Zero Voltage Transition (ZVT) buck converter and Zero Current Transition (ZCT) buck converter. Results can easily be expanded to other resonant converter classes since their operation usually is explained using similar Zero-Voltage Transition (ZVT) and Zero-Current Transition (ZCT).

While resonant buck converters are used in many applications, the failure rate for each application has a 
different structure:

- Converters working with low-voltage (under 20 Volts), high-current (hundreds of Amperes) in telecom and computer applications have the system lifetime strongly dependent on the output capacitor bank. In such case, a multitude of capacitors are used in parallel to satisfy the ripple requirement at said large current. When their effect is compared to the effect of semiconductors in overall lifetime calculation, this set of 10-20 capacitors contributes more.

- Converters operated at higher voltage (hundreds of Volts) and lower current (under 50 Amperes) within solar applications have a failure rate strongly dependent on the power semiconductor transistors due to their limited capacitance. When their effect is compared to the effect of semiconductors in overall lifetime calculation, the semiconductors contribute more.

Since the contribution to reliability probability and lifetime calculation of the input/output filters and the control electronics is similar for the converter with or without resonance, this article limits the study to the implications of parameter variation to the failure rate and reliability probability for the power semiconductors and eventual resonant circuit. This is better understood when equations are developed in Section V.

Control solutions for either of Zero Current Transition (ZCT) and Zero Voltage Transition (ZVT) are reported in numerous research papers [27-30] and control integrated circuits are made specifically for this class of converters.

This paper follows a preliminary study [32] where the switching frequency range for a ZVT buck converter was limited to $10 \%$ range by the control ICs while the parameters of the passive components are allowed to vary within $+/-25 \%$. The current paper justifies in Section III a narrower interval for the variation of the passive components based on datasheet and manufacturer information. Thus, calculation of reliability is mostly possible without hitting the frequency limits.

After the problem is stated and explained in Section I, Section II reviews some essential theory behind the resonant buck converters operated with either of Zero Current Transition (ZCT) and Zero Voltage Transition (ZVT). Section III appraises the ageing and after-shock variation of parameters in passive components. Section IV illustrates practically the operation with misalignment control for either of Zero Current Transition (ZCT) and Zero Voltage Transition (ZVT) buck converters. Finally, Section V offers an example of reliability calculation, and Section VI sums up conclusions. In the context of this paper, the misalignment corresponds to the case of a change in parameters of passive components that makes the original design obsolete.

The main contributions of the article are as follows:

- Reviews literature and sums up the possible causes for ageing and after-shock parameter variations for various technologies of inductance or capacitor components. This analysis demonstrates dependency of technology selection on results at each voltage level. This review led to the selection of a ceramic capacitor with a capacitance value change of $2 \%$ per hour-decade and an inductor with an inductance value change of $4 \%$ per hour-decade, both used to estimate the effect of component ageing to the lifetime and reliability calculation.

- Builds a strong argument for the problem of misalignment control of resonant converters due to ageing and quantifies analytically its effects into reliability. On this respect, the paper illustrates practically thermal effects of control misalignment for either of ZCT and ZVT converters.

- Provides an example for calculation of lifetime for resonant converters since this is not available in literature. In this respect, the paper develops a primer in Excel for the calculation of reliability of a power converter. These instruments are scalable as they can be further used for any other resonant converter to the extent that any resonant converter can be reduced at a ZVT or ZCT operation.

\section{RESONANT BUCK CONVERTERS}

\section{A. ZVT Conversion}

The resonant buck converter builds upon a conventional buck converter where a series inductance $L_{r}$ and a parallel capacitor $C_{r}$ have been added near the power transistor, Fig. 1. The important transition moments can be seen on Fig. 2.

The equations related to operation of resonant buck converters are presented in Appendix, and these demonstrate that a proper operation can be achieved within certain operation conditions only.

Within a conventional buck converter, the switching instants are defined based on the duty cycle required to produce a certain output voltage. For a resonant converter, additional limits for operation are imposed to maintain either zero-voltage or zero-current capability. These values are dependent on $L_{r}$ and $C_{r}$ as well as on the load current $I_{L}$ and converter's input voltage $E$. For unified design, the components $\left(L_{r}\right.$ and $C_{r}$ ) added to the circuit for the resonant swing, can be characterized jointly with a resonant frequency $f_{r}$ and a characteristic impedance $Z_{r}$.

$f_{r}=\frac{1}{T_{r}}=\frac{1}{2 \cdot \pi \cdot \sqrt{L_{r} \cdot C_{r}}}$

$Z_{r}=\sqrt{\frac{L_{r}}{C_{r}}}$

Passive components are considered with constant parameters in conventional design process and the load current becomes the only variable parameter during the operation. The $Z V T$ resonant circuit works properly when:

$Z_{r} \cdot I_{L} \geq E$

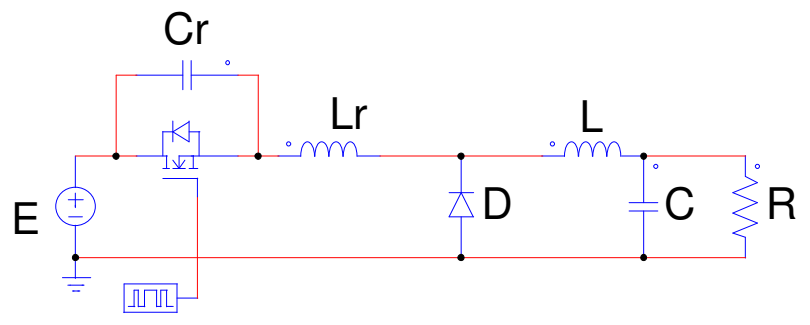

Fig. 1: Principle of the ZVT Resonant Buck Converter 

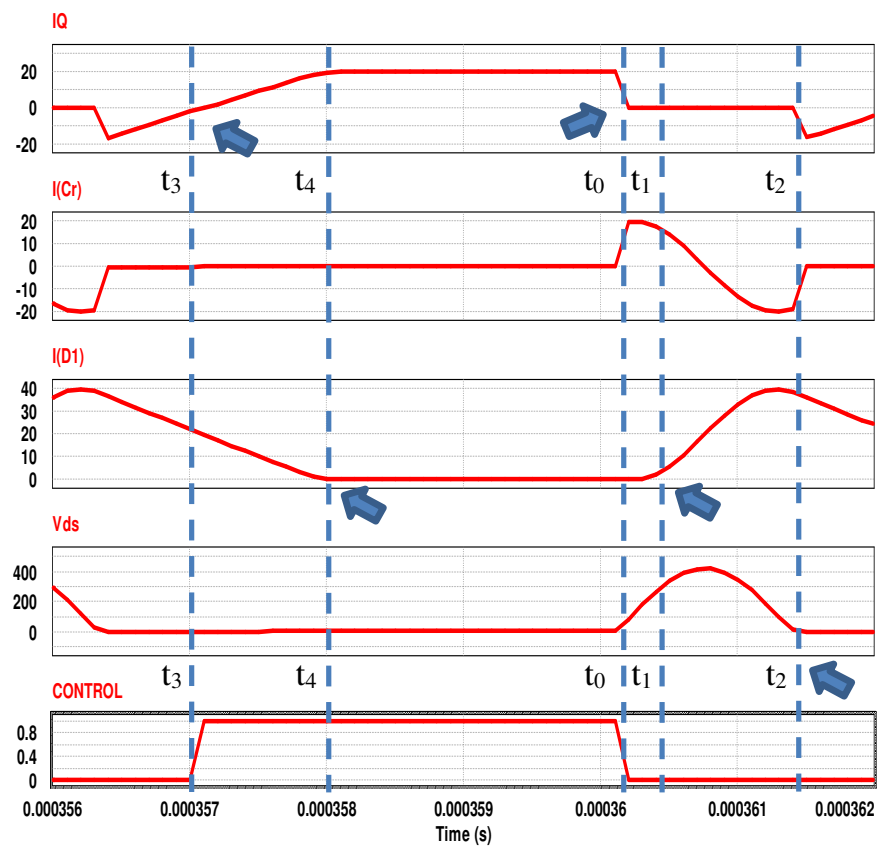

Fig. 2 Waveforms for operation of the ZVT Resonant Buck Converter

Considering a resonant operation at any current above $40 \%$ of the maximum load current yields:

$\sqrt{\frac{L_{r}}{C_{r}}} \cdot 0.4 \cdot I_{L} \geq E$

This design example considered in Table I leads to:

$\frac{L_{r}}{C_{r}} \geq 225 \rightarrow L_{r}=5 \mu H ; C_{r}=22 n F$

TABLE I

COMPLETE DATASET FOR THE SIMULATION-BASED TESTS

\author{
Common for both ZVT and ZCT \\ MOSFET Transistor IRFP460 \\ Gate voltage $=20 \mathrm{~V}$ \\ Gate resistance $=4.3 \Omega$ \\ Ambient temperature $=25^{\circ} \mathrm{C}$ \\ Power Diode CS240650 \\ Supply voltage $120 \mathrm{~V}$ \\ Output voltage $48 \mathrm{~V}$ (potential telecom application)
}

\section{ZVT buck converter}

Variable load current, maximum at $20 \mathrm{~A}$

Power semiconductor transistor, nominal frequency $197 \mathrm{kHz}$

Duty cycle for operation at $20 \mathrm{~A}, \sim 61 \%$

\section{ZCT buck converter}

Variable load current, maximum at $12 \mathrm{~A}$

Power semiconductor transistor, nominal frequency $165 \mathrm{kHz}$

Thence, conclusions for the proper operation yield.

- ZVT can be obtained for certain current levels while light loads do not reduce power transistor switching loss.

- Since the duration of the off-state is dictated by the circuit conditions, the resonant buck converter can control the output voltage only by changing the period of the entire cycle using a variable control frequency.

\section{B. Dependency on parameters of ZVT converter}

Observing waveforms in Fig. 2 yields (see Appendix):
$V_{\text {out }}=E \cdot\left[1-\frac{t_{\text {zero }}}{T}\right]+E \cdot \frac{1}{2} \cdot \frac{E}{I_{L}} \cdot \frac{1}{\omega_{r} \cdot Z_{r}}$

where (demonstration not included herein)

$t_{\text {zero }}=t_{4}-t_{0}=\frac{E}{I_{L}} \cdot \frac{1}{\omega_{r} \cdot z_{r}}+\frac{1}{\omega_{r}} \cdot\left[\pi+\arcsin \left(\frac{E}{Z_{r} \cdot I_{L}}\right)\right]+\frac{1}{\omega_{r}}$.

$\frac{z_{r} \cdot I_{L}}{E} \cdot\left[1+\sqrt{\left[1-\left[\frac{E}{z_{r} \cdot I_{L}}\right]^{2}\right]}\right]$

Fig. 3 plots eqs. (6-7) and illustrates the variation of the output voltage for a variation of the parameters $L_{r}, C_{r}$ with $\pm 25 \%$ for the converter considered in Fig. 1 and numerical example in Table I. Due to the complex resonance processes, the output voltage yields lower than the equivalent hardswitched buck converter case, operated with the same duty cycle. Both examples in Fig. 3 show that the highest output voltage is achieved when $L_{r}$ and $C_{r}$ are at their lowest value within the variation range, $-25 \%$ in example. The variation of the output voltage has a maximum of $\sim 40 \%$ from nominal.
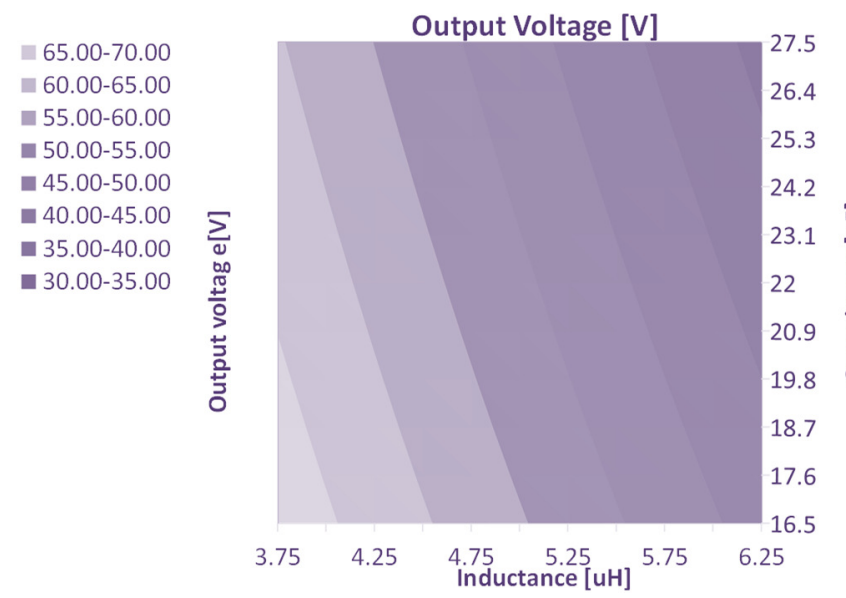

(a) Output voltage in [V] for ideal operation, for load current of $20 \mathrm{~A}$, and switching frequency of $197 \mathrm{kHz}$.

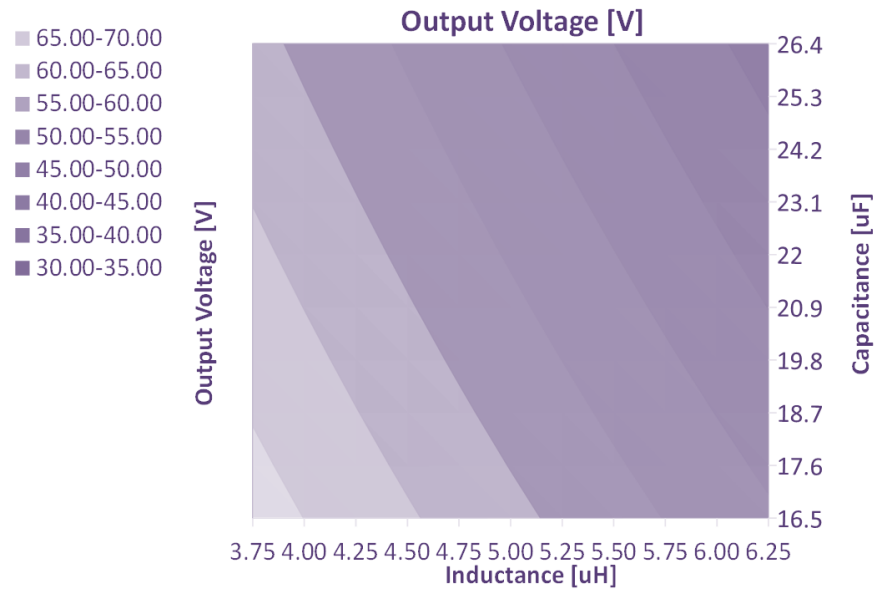

(b) Output voltage in [V] for ideal operation, for load current of 12 A (60\%), and switching frequency of $247 \mathrm{kHz}$.

Fig. 3 Microsoft Excel contour graphs for variation of the output voltage at parameter variation, for the numerical data set from Table 1 , calculated for ideal conditions, using (6-7).

In order to compensate for the steady-state error of the output voltage, a closed-loop system is adjusting the switching frequency. This principle is very used in the design of control integrated circuits (ICs). Among numerous examples of ICs controlling resonant converters with a variable switching frequency as result of the closed-loop control, it is worth 
noting LD405, GP605, CS3805, UC3860, UC1861, UC1864, UC1865, MC34066, and CS360. All these ICs adjust the timing range with external resistors and capacitors.

Fig. 4 demonstrates that a variation in the range of $\pm 25 \%$ of the parameters $L_{r}, C_{r}$ produces a variation of the control period within the same $\pm 25 \%$ range.

\section{Control PWM period [usec]}

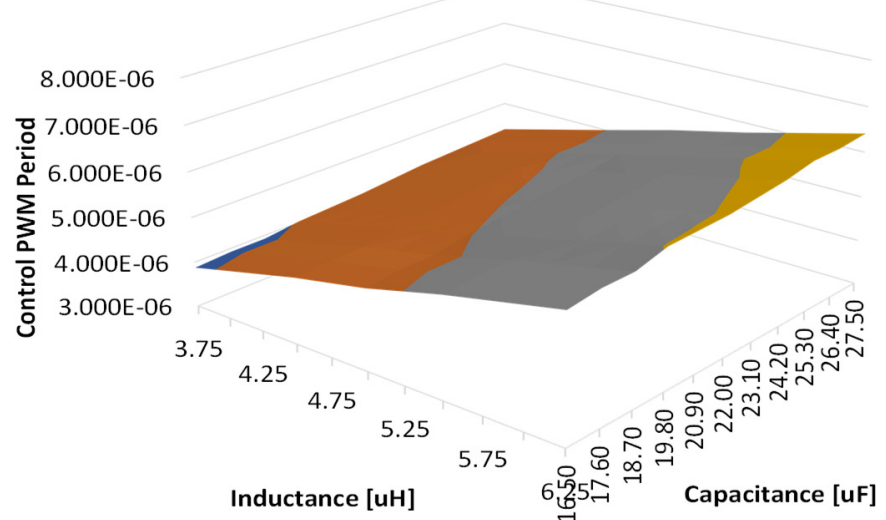

Fig. 4 Variation of the switching period at parameter values used to keep the output voltage constant under a load current of $20 \mathrm{~A}$

\section{Zero-Current Transition (ZCT) Buck Converter}

As an alternative to the ZVT converter, resonant circuits for Zero Current Transition (ZCT) of a buck converter are shown in Fig. 5(a or b). This article considers the solution in Fig. 5(a) and significant waveforms are provided with Fig. 6.

The key to the entire operation is to have enough energy within the resonant operation so that the current through $L_{r}$ reaches zero. The constraint is defined as:

$Z_{r} \cdot I_{L}=\sqrt{\frac{L_{r}}{C_{r}}} \cdot I_{L} \leq E$

This design leads to:

$\frac{L_{r}}{C_{r}} \leq 100 \rightarrow L_{r}=3.3 \mu \mathrm{H} ; C_{r}=68 n F$

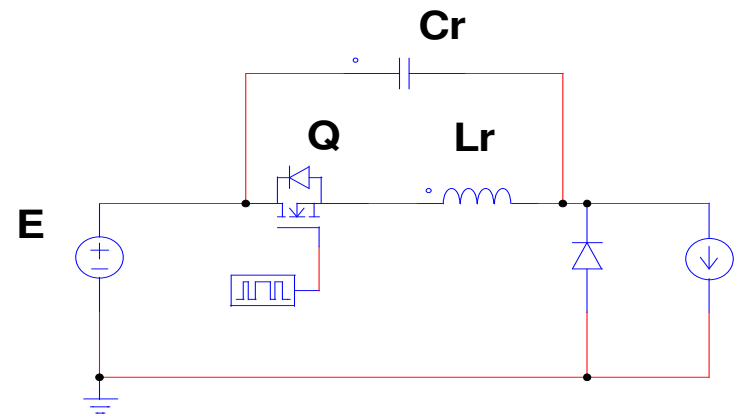

Io

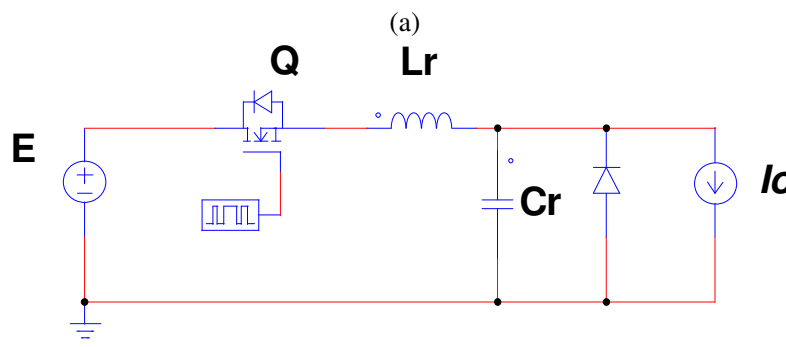

(b)
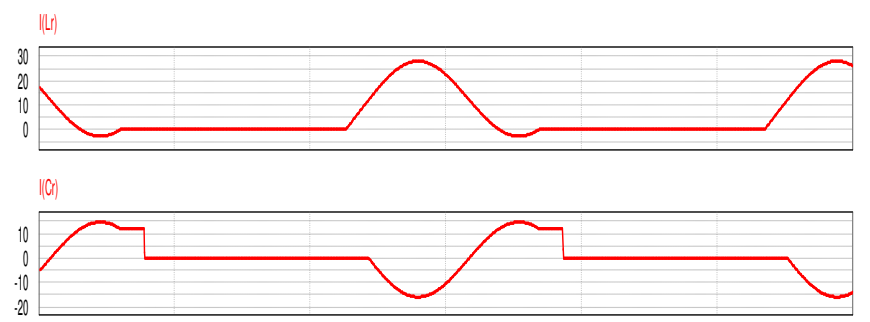

$(10)$

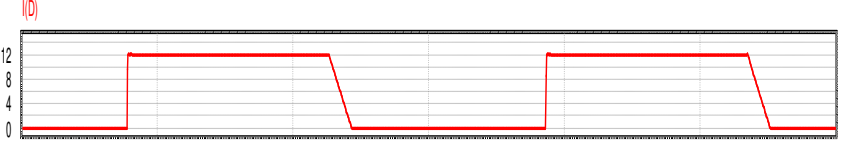

va
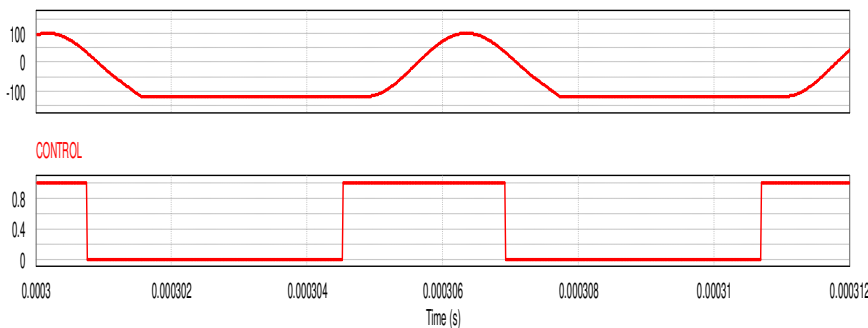

Fig. 6 Waveforms for operation of the ZCT Resonant Buck Converter

\section{Output Voltage [V]}

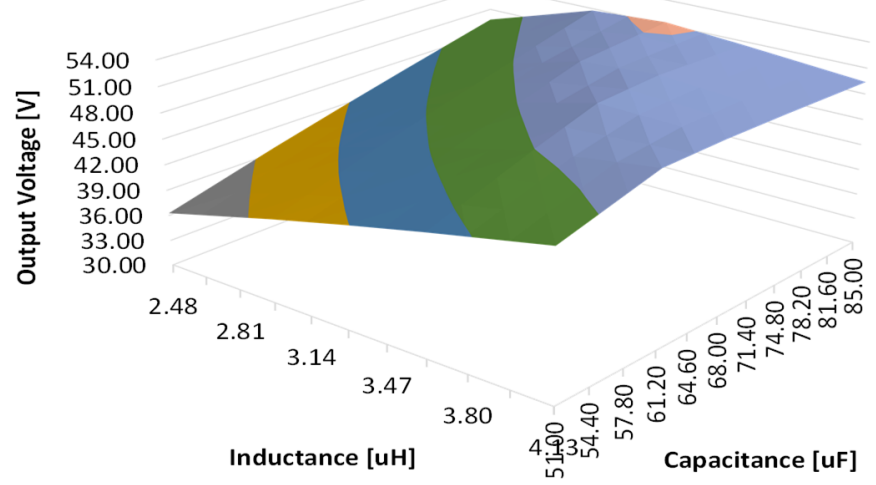

Fig. 7 Variation of the ZCT converter's output voltage at parameter variation, for dataset from Table I, calculated for ideal conditions.

\section{Dependency on parameters of ZCT converter}

It is important to note that the output voltage depends on the resonant period which governs the conduction interval for the main transistor.

$\frac{V_{o}}{E}=\frac{T_{r}}{T}$

It yields:

$\frac{V_{o}}{E}=\frac{1}{T} \cdot 2 \cdot \pi \cdot \sqrt{L_{r} \cdot C_{r}}$

Fig. 7 shows that the output voltage is very sensitive to the $L_{r}, C_{r}$ parameter variation (herein, $\pm 25 \%$ ) without control. The control should adjust switching frequency with a constant duty cycle for a limited range, or consider a fixed on-time and vary both duty cycle and switching frequency for a wider range. The control is therefore more difficult than for ZVT converter.

Fig. 5 Quasi-resonant circuit for ZCT 


\section{III.AGEING AND AFTER-SHOCK PARAMETER VARIATION FOR THE PASSIVE COMPONENTS}

This Section reviews possible causes for parameter degradation in passive components and estimates the maximum amount for this variation based on component data. This would be further considered in our analysis for a calculation in reliability effects.

Ageing and after-shock parameter variation of the $L_{r}, C_{r}$ passive components possibly lead to a deterioration of the resonant constraint. As a mostly-neglected secondary effect, these also deteriorate the reliability performance and reduce the lifetime of the converter.

Ageing is a normal development when using the passive components continuously, even if under nominal conditions. The most obvious consequence of ageing for passive components consists of an increase of calorimetric (resistive) loss. However, certain technologies for fabrication of passive components are demonstrated to produce a variation of the nominal values of the main parameter, either inductance [1618] or capacitance [19-25]. This is a contemporary research topic [16-25] and a series of recent papers [26-27] have addressed the effects of parameter variation due to ageing. A review of literature is next summarized.

Ceramic capacitors [19-22] usually have a decrease of capacitance with age at a rate of $1 \%$ per logarithmic decade of hours, depending on their dielectric:

- Dielectric class C0G (similar to Teflon film capacitors) observe a negligible change in capacitance $[21,22]$.

- Dielectric class X7R/X5R (the second character indicates the maximum temperature: 5 corresponds to $85^{\circ} \mathrm{C}$, and 7 corresponds to $125^{\circ} \mathrm{C}$ ) observe a decrease of capacitance with $1-2.5 \%$ per hour-decade. The spec for --R capacitors (X5R/X7R) is of $\pm 15 \%$ maximum capacitance change over the operational temperature range $[21,22]$, that is the best among all classes. This is not important for resonant converters where the temperature is kept at bay.

- Dielectric class Z5U observe a decrease of capacitance with $6 \%$ per decade [21], and it is not recommended for resonant converters.

In the last two classes, the ageing process can be reset by heating the dielectric above its Curie Point, which is actually impossible in a practical power converter.

Metallized Film capacitors [25] are also seeing a negative decrease in capacitance at a rate $\sim 0.5 \%$ per 1,000 -hour at polypropylene and $\sim 1 \%$ per 1,000-hour at polyester. In both cases, operation with high ripple current and voltage close to rating prominently accelerate degradation.

The aluminum and tantalum capacitors [23-24] go through a gradual (linear) decrease in capacitance over time at a higher rate ( 10\%/100-hour) than ceramic or film capacitors. This may affect the output filter which is not the topic herein.

Unlike the ageing degradation of capacitors, the degradation of inductor [16-18] demonstrates a greater dispersion, and it is difficult to quantify analytically. However, the inductance shows a negative change in time $(\sim 10 \%$ for thick film inductors, to 1,000-hours). Despite the lack of unanimously agreed value for the rate of ageing, we have inferred $4 \%$ as a worthy benchmark for our analysis.

All of the above consider otherwise ideal operation conditions. This means that additional heat produced by increased resistive loss or change in capacitance are not accounted for, even if these also accelerate degradation.

Most aluminum or electrolytic capacitors are rated to 10,000-hours only, which seems too low since continuous usage during one year means 8,760-hours. Hence, these need to be used in de-rated condition for bus voltage and current ripple. Alternatively, special capacitor classes, usually called ultra-long-life aluminum electrolytic capacitors (for example, LLE series from Nichicon), are designed to satisfy the 15-20 years lifetime rating of the entire equipment.

Some manufacturers offset loss of capacitance from time of measurement to the first 1,000-hour age by using asymmetric inspection tolerances. For example, if it is known that the total capacitance loss to 1,000 -hour will be $5 \%$, then the capacitors may have the production end inspection set to $-15 \% /+25 \%$ tolerances instead of more common $\pm 20 \%$ tolerances. The production end tolerance represents the maximum expected range in capacitance compared to its listed value.

Otherwise, class 2 dielectrics such as X7R and X5R need to be operated far from voltage rating since they lose significant capacitance as operation approach the rated voltage. There is also a capacitance change possible with temperature, for instance X5R dielectric observes $5 \%$ decrease for each $20^{\circ} \mathrm{C}$ increase above $40^{\circ} \mathrm{C}$.

Given these considerations, the best choice for the resonant tank capacitor consists of a NP0-type (negative-positive-zero $\mathrm{ppm} /{ }^{\circ} \mathrm{C}$ ) multilayer ceramic capacitor. NP0 Ceramic Capacitors (also coded $\mathrm{COG}$ ) are made from a mixture of titanium oxides and are temperature-compensating devices. Other materials include neodymium, samarium, and other rare earth oxides. It means that it has a flat response across a wide range of temperatures and age better. This class of capacitors is not available at higher voltages, maybe the widest range available could be $100 \mathrm{nF} @ 50 \mathrm{Vdc}$. The possible lack of available NP0-type capacitors justifies the need for this article especially when using other capacitor classes in resonant converters.

Another effect consists in a change of the main parameter (inductance, capacitance) due to an operational shock, like the inductor's current or the capacitor's voltage would occasionally go to an unexpectedly high value. Effects like dielectric absorption or magnetic remanence became more visible in modern time due to reduction of other imperfections with technology improvement. These aspects are more difficult to model and there are less important reference papers with a complete description.

In a review conclusion for our study, this application implies the selection of a ceramic capacitor (X7R or X5R) with a capacitance value change of $2 \%$ per hour-decade $[21,22]$, and an inductor with an inductance value change of $4 \%$ per hour-decade [16-18]. This article estimates the effect of component ageing to the lifetime and reliability calculation. 


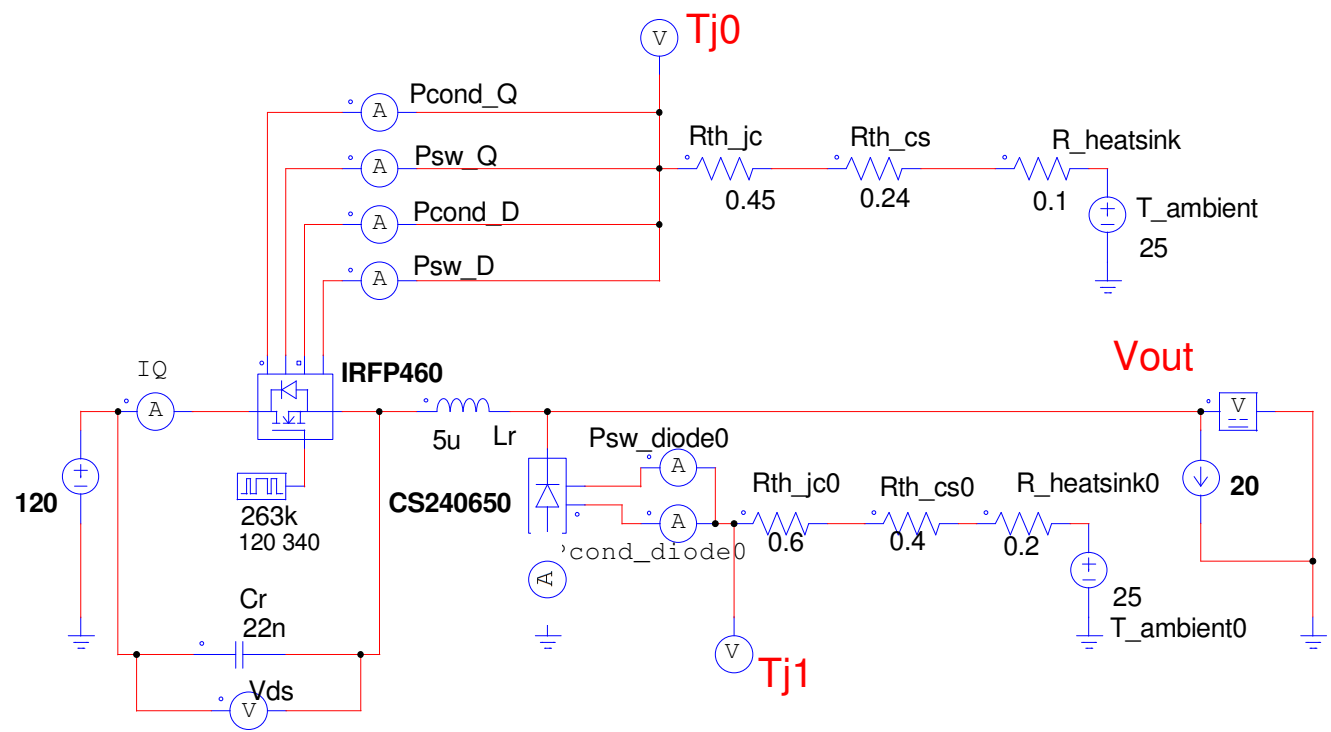

Fig. 8. Model for the thermal analysis of a ZVT buck converter at nominal.

\section{IV.OPERATION WITH VARIABLE FREQUENCY}

Since the lifetime calculation strongly depends on the operational temperature of the power semiconductor transistors, a precise evaluation of power loss and temperature is required. This can be achieved with one of the two methods.

- A high-level simulation model for the power semiconductor transistor associated with a systematic parameter variation [32].

- A thermal camera monitoring when parameters are changed, under a test duration time penalty [34].

This Section analyses the thermal behavior of the resonant buck converter under a parameter variation. The analysis is performed with thermal models in PSIM simulation [33] PSIM software system comes with thermal models for power transistors, that simply replicate datasheet information. Given its wide acceptance by industry, the software product has the same guarantee of accuracy as an oscilloscope product. Using a simulation tool can save hours of analysis at various operation points.

The goal of this test is to evaluate the thermal effects of an operation with misalignment due to resonant component variation.

\section{A. ZVT Circuit}

A PSIM thermal model for ZVT buck converter is built in Fig. 8. The loss components for semiconductors are based on datasheet energy loss information embedded within the PSIM model. Loss power components are therefore compiled from graphs based on $\mathrm{E}_{\mathrm{on}}$ and $\mathrm{E}_{\text {off }}$ energies, rather than calculated as a current-voltage product. The static junction temperature value is calculated with an equivalent electrical circuit. The computation ripple is within $0.17 \%$ at $10 \mathrm{~ns}$ fixed step.

Tests for ZVT converter are performed at a nominal load current of $20 \mathrm{~A}$ and collected for variation of the inductance and capacitance values, from nominal to a maximum of $\pm 15 \%$. An interval centered on nominal parameter (capacitance or inductance) is considered for sake of completeness, despite knowing that capacitance change is negative and logarithmic in respect to time, Section III.

The junction temperature is observed in Fig. 9 when the duty cycle is maintained constant at around 0.61 , and the frequency is changed to keep the output voltage in track, within a wide range of $157-263 \mathrm{kHz}$ around the nominal switching frequency of $197 \mathrm{kHz}$ (dataset of Table I).

If both $\mathrm{L}_{\mathrm{r}}, \mathrm{C}_{\mathrm{r}}$ decrease due to ageing, transient processes are faster and the output voltage yields larger, closer to the conventional buck converter value. The control system keeps duty cycle constant and increases switching frequency to decrease output voltage. This produces a decrease in effective pulse duration and remakes the "bad trapezoidal shape" of the current as it was seen at nominal operation. This further results in less conduction loss at such higher switching frequency, like a thermal self-compensation.

\section{B. ZCT Circuit}

A PSIM thermal model for the ZCT buck converter is similarly built around IRFP460 MOSFET transistor and a Powerex CS240650 diode, Fig. 10. Tests are performed at a nominal load current of $12 \mathrm{~A}$ and collected for variation of the inductance and capacitance values, from nominal to a maximum of $\pm 25 \%$. The junction temperature is observed in Fig. 11 when control of the output voltage is achieved with a constant on-time and variable frequency in a range $147-212$ $\mathrm{kHz}$ (nominal switching frequency of $162 \mathrm{kHz}$ ).

Similar to the ZVT case, the reliability and lifetime calculation must observe the worst case, that is this maximum value of the junction temperature. The worst case occurs herein when the capacitor reaches a large value and the inductor are at its lowest values. The negative decrease in capacitance (demonstrated in Section III for different capacitor classes) does not have a major impact in lifetime of a ZCT converter. From this point of view, the ZCT converter is more advantageous than the ZVT buck converter. 


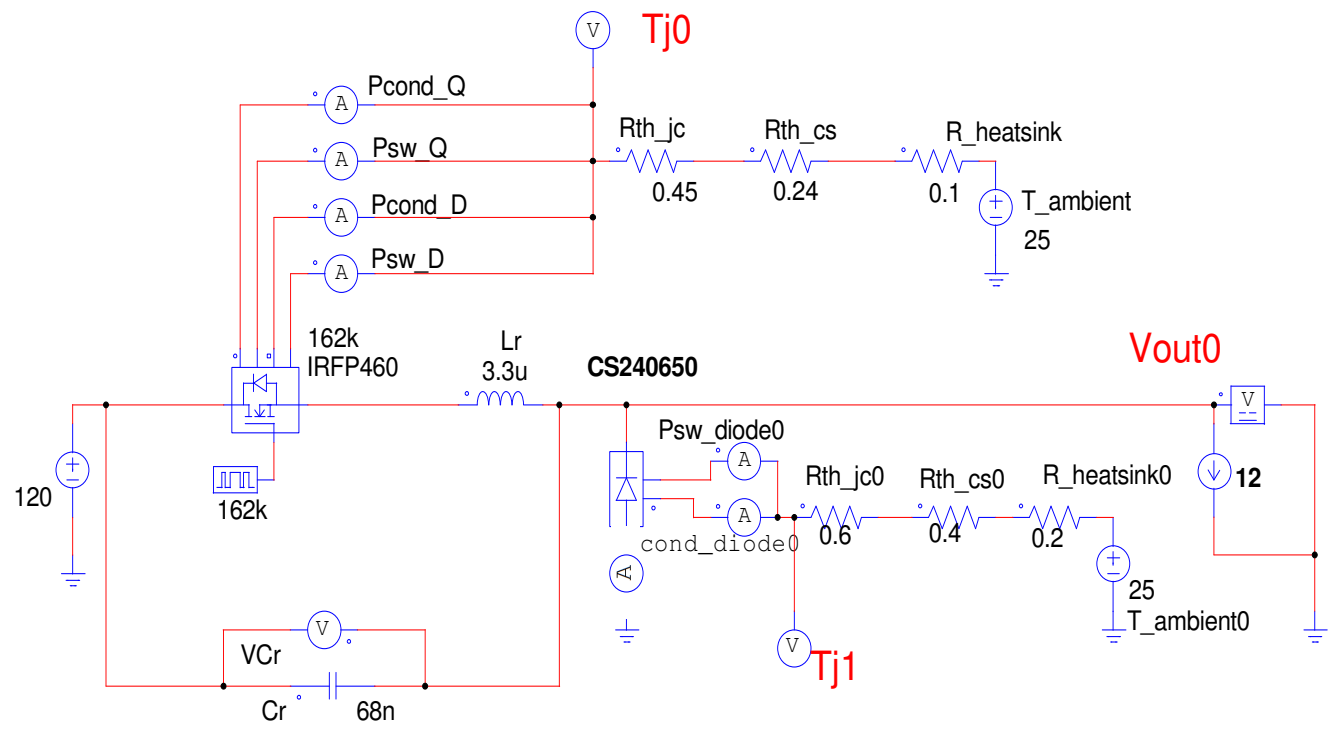

Fig. 10 Model for the thermal analysis of a ZCT buck converter at nominal.

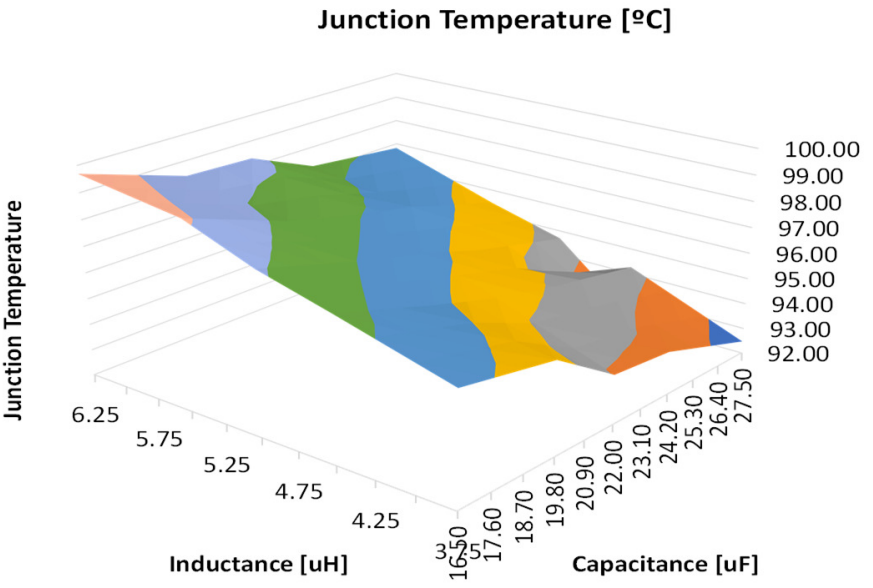

Fig. 9 Transistor junction temperature (Celsius) for ZVT converter with a constant output voltage and under a load current of $20 \mathrm{~A}$. The thermal model for the MOSFET transistor includes $\mathrm{R}_{\mathrm{th} \_\mathrm{jc}}=0.45{ }^{\circ} \mathrm{C} / \mathrm{W}, \mathrm{R}_{\mathrm{th} \_\mathrm{cs}}=0.24^{\circ} \mathrm{C} / \mathrm{W}$, $\mathrm{R}_{\text {th_heatsink }}=0.10^{\circ} \mathrm{C} / \mathrm{W}$, ambient temperature of $25^{\circ} \mathrm{C}$.

\section{Junction Temperature $[\stackrel{\circ}{ } \mathrm{C}]$}

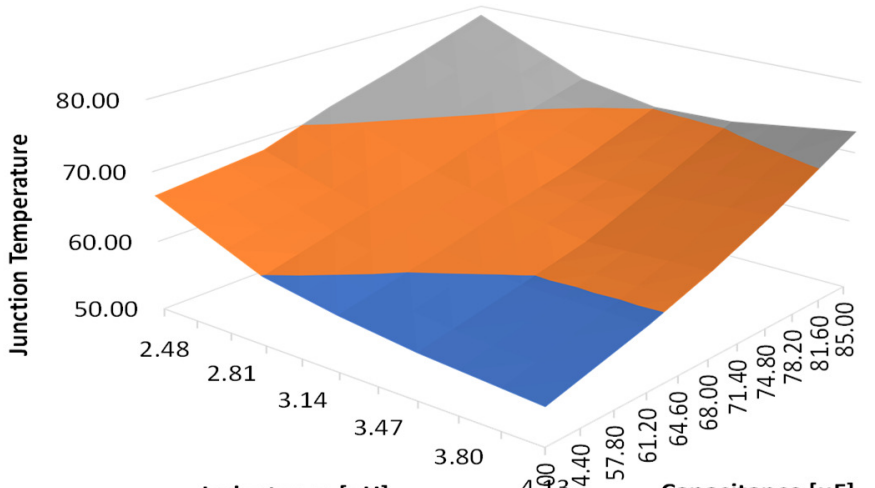

Inductance $[\mathrm{uH}]$

Capacitance [uF]

Fig. 11 Transistor junction temperature (Celsius) for the ZCT converter with a constant output voltage and under a load current of $12 \mathrm{~A}$. The thermal model for the MOSFET transistor includes $\mathrm{R}_{\text {th_jc }}=0.45{ }^{\circ} \mathrm{C} / \mathrm{W}, \mathrm{R}_{\text {th_cs }_{-}}=0.24{ }^{\circ} \mathrm{C} / \mathrm{W}$, $\mathrm{R}_{\text {th_heatsink }}=0.10{ }^{\circ} \mathrm{C} / \mathrm{W}$ and ambient temperature of $25^{\circ} \mathrm{C}$.

\section{RELIABILITY CALCULATION}

\section{A. Theory}

Failure rate is the frequency with which a system fails, expressed in failures per unit of time. In a simplified approach, the reliability calculation can consider the failure rate as being constant during the lifetime of the system. However, parameter variation justifies a time-varying failure rate, which slightly complicates calculation.

For a power converter, all components are considered equally important and the failure rate of a system is the sum of the failure rates for each individual component. This means that the overall failure rate yields:

$\lambda_{\text {SYSTEM }}=\sum_{i=1}^{N} \lambda_{i}$

where $\lambda_{i}$ corresponds to the individual failure rates of the components, like power semiconductors, capacitors, or inductors. For the resonant converter, the failure rate yields:

$\lambda_{\text {SYSTEM }}=\lambda_{\text {MOSFET }}+\lambda_{\text {CONTROL }}+\lambda_{\text {DIODE }}+\lambda_{\text {INDUCTOR }}+$ $+\lambda_{\text {OUT_CAPACITOR }}+\lambda_{L r}+\lambda_{\text {Cr }}$

Each individual component (or term in (13) ) is considered to have a known and constant failure rate $\left(\lambda_{\text {base }}\right)$, which is further de-rated through a series of stress factors.

$\lambda=\lambda_{\text {base }} \cdot \prod_{i=1}^{m} \pi_{i}=\lambda_{\text {base }} \cdot \pi_{T} \cdot \pi_{V} \cdot \pi_{A} \cdot \pi_{R} \cdot \pi_{E} \cdot \pi_{C} \cdot \pi_{Q}$

In the most complete form, these stress factors refer to temperature $\left(\pi_{T}\right)$, voltage stress $\left(\pi_{V}\right)$, circuit/application $\left(\pi_{A}\right)$, rating $\left(\pi_{R}\right)$, environment $\left(\pi_{E}\right)$, construction $\left(\pi_{C}\right)$, and product quality $\left(\pi_{Q}\right)$. Some of these stress factors have similar values for conventional and resonant converters, some are different due to their actual operation point.

The numerical characterization (forecast) of these stress factors comes from the actual model used for calculation, and it is consistent in standards like MIL-HDBK-217, IEC TR62380, or FIDES. The values of the stress factors are provided in tables of the standard which use various application parameters for reading. Not unlike a weather report, a proper design procedure should consider all forecast 
methods for calculation within the worst possible operation mode, and conclude after observation of the worst result, that is the shortest lifetime expectancy.

MIL-HDBK-217 [13] is an older US military standard with data based on a wide collection of results. Regrettably, it does not provide enough detail on certain new technologies for inductors and capacitors. From this point of view, the novel International Electrotechnical Commission's TR62380 [14] is more successful. Dependence of reliability calculations of different standards on the temperature has been analyzed and it has been shown that the temperature has a little influence on calculations in IEC TR62380 and a great dependency on the temperature with FIDES [15] and MIL-HDBK-217.

Finally, the FIDES method [15] shows no dependency on the voltage stress. In most cases, this does not matter since the designers of the circuits always rate voltage far enough from the nominal voltage.

\section{B. ZVT, using MIL-HDBK-217}

A ZVT buck converter setup is considered for load current under $20 \mathrm{~A}$ load and a $48 \mathrm{~V}$ output voltage, when supplied from $120 \mathrm{~V}$. Three converter structures are considered herein:

- Ideal resonant converter, without parameter variation (case "1" below).

- A resonant converter, controlled with constant duty cycle and variable frequency for constant output voltage when $(-25 \%)$ parameter variation occurs (case " 2 " below).

- A conventional buck converter (case "3" below).

What concerns data in Table II, the conduction loss for the switch in the resonant converter is higher than the conventional case because the conventional current is augmented by the resonant current. Conversely, the switching loss in the switch is drastically reduced due to switching at or near zero current. The sum of conduction and switching losses may be or not larger than the conventional case. Hence, a proper comparison should also include the diode in the same converter. Whenever the conduction loss is dominant for the switch due to the duty cycle, it is not for the diode. In cases when the input and output voltages are fixed by applications, the overall loss (that is switch plus diode) should be considered for a comparison (herein, $105 \mathrm{~W}$ for resonant converter and $138 \mathrm{~W}$ for conventional converter).

The same failure rate can be considered for the control circuit and the main passive components (buck inductor and the output capacitor) in either of the three circuits. The investigation in the current article is constrained to the lifetime contribution from the main power semiconductors and the added resonant components. The previous models provide data from Table II for ZVT buck converter and it demonstrates that parameter variation is not a concern.

The considered system-level failure rate for the three converters yield as follows.

$\Delta \lambda_{1}=\lambda_{M O S F E T, 1}+\lambda_{D I O D E, 1}+\lambda_{L r, 1}+\lambda_{C r, 1}$

$\Delta \lambda_{2}=\lambda_{M O S F E T, 2}+\lambda_{D I O D E, 2}+\lambda_{L r, 2}+\lambda_{C r, 2}$

$\Delta \lambda_{3}=\lambda_{M O S F E T, 3}+\lambda_{D I O D E, 3}$

The power MOSFET device has a failure rate as follows.

$\lambda_{\text {MOSFET }}=\lambda_{\text {base }} \cdot \pi_{A} \cdot \pi_{T} \cdot \pi_{V} \cdot \pi_{Q} \cdot \pi_{E}$
TABLE II

THERMAL RESULTS FROM PSIM ANALYSIS

\begin{tabular}{|l|c|c|c|}
\hline \multicolumn{1}{|c|}{ Parameter } & Case 1 & Case 2 & Case 3 \\
\hline$L_{r}, C_{r}$ & $5 \mu H, 22 n F$ & $3.75 \mu H, 16.50 n F$ & $n / a$ \\
\hline Output voltage [V] & 48.17 & 48.10 & 48.17 \\
\hline Sw.freq [kHz] & 197 & 263 & 197 \\
\hline Dutycycle & 0.61 & 0.61 & 0.44 \\
\hline Pcond_Q $[\mathrm{W}]$ & 89.23 & 89.07 & 79.73 \\
\hline Psw_Q $[\mathrm{W}]$ & 0.10 & 0.16 & 6.63 \\
\hline$T j \_Q\left[{ }^{\circ} \mathrm{C}\right]$ & 96.35 & 96.25 & 93.29 \\
\hline Pcond_D $[\mathrm{W}]$ & 15.21 & 15.22 & 14.31 \\
\hline Psw_D $[\mathrm{W}]$ & 0.30 & 0.50 & 36.59 \\
\hline$T j \_D\left[{ }^{\circ} \mathrm{C}\right]$ & 43.62 & 43.88 & 86.09 \\
\hline
\end{tabular}

The stress factors refer to temperature $\left(\pi_{T}\right)$, voltage stress $\left(\pi_{V}\right)$, circuit/application $\left(\pi_{A}\right)$, environment $\left(\pi_{E}\right)$, and product quality $\left(\pi_{Q}\right)$.

All terms in (18) are depicted from MIL-HDBK-217F (notice 2 of February $28^{\text {th }}, 1995$ ):

- Base failure rate for a low-frequency Si FET (page $6.8 / 61$ ) is 0.012 .

- Application factor $\pi_{A}=10$, for power above $250 \mathrm{~W}$.

- Environment factor $\pi_{E}=6$, for application classified as "Ground, Fixed".

- Quality factor $\pi_{Q}=2.4$, for production of discrete semiconductors ("JAN").

- Voltage factor is considered as unitary.

- Temperature factor $\pi_{T}$ depends strongly on temperature within a ratio of $1: 8.7$. This leads to 3.4 at $\sim 95^{\circ} \mathrm{C}$.

Using these numerical values helps calculation of the contribution to failure rate as follows.

$\lambda_{\text {MOSFET }, 1} \cong \lambda_{\text {MOSFET }, 2} \cong \lambda_{\text {MOSFET }, 3}=\lambda_{\text {base }} \cdot \pi_{A} \cdot \pi_{T} \cdot \pi_{V}$. $\pi_{Q} \cdot \pi_{E}=0.012 \cdot 10 \cdot 6 \cdot 2.4 \cdot 1 \cdot 3.4=\frac{5.87 F}{10^{6} h}=5,875 F I T$

As per MIL-HDBK-217F (notice 2 of February $28^{\text {th }}$, 1995), a power Si diode has a failure rate as follows.

$\lambda_{\text {DIODE }}=\lambda_{\text {base }} \cdot \pi_{C} \cdot \pi_{T} \cdot \pi_{V} \cdot \pi_{Q} \cdot \pi_{E}$

The stress factors depend on application and can be identified for each of the three cases selected for our analysis as being the same except for the temperature.

- Base failure rate for a low-frequency fast-recovery Si diode (Page 6.1/55) is 0.025 .

- Construction factor $\pi_{A}=1$.

- Environment factor $\pi_{E}=6$, for application classified as "Ground, Fixed".

- Quality factor $\pi_{Q}=2.4$, for production of discrete semiconductors ("JAN").

- Voltage factor is considered as unitary.

- Temperature factor: $\pi_{T}=1.5$ at $\sim 45^{\circ} \mathrm{C}$ and $\pi_{T}=3.0$ at $\sim 85^{\circ} \mathrm{C}$.

The diode lifetime is calculated as follows.

$\lambda_{D I O D E, 1}=\lambda_{D I O D E, 2}=\lambda_{\text {base }} \cdot \pi_{C} \cdot \pi_{T} \cdot \pi_{V} \cdot \pi_{Q} \cdot \pi_{E}=0.025 \cdot$

$1 \cdot 6 \cdot 2.4 \cdot 1 \cdot 1.5=\frac{0.54 F}{10^{6} h}=540 F I T$

$\lambda_{D I O D E, 3}=\lambda_{\text {base }} \cdot \pi_{C} \cdot \pi_{T} \cdot \pi_{V} \cdot \pi_{Q} \cdot \pi_{E}=0.025 \cdot 1 \cdot 6 \cdot 2.4$.

$1 \cdot 3=\frac{1.08 F}{10^{6} h}=1080 F I T$ 
The resonant capacitor contributes to the failure rate. $\lambda_{\text {Ceramic }}=\lambda_{b} \cdot \pi_{Q} \cdot \pi_{E} \cdot \pi_{C V}=0.00075 \times 1 \times 10 \times 2=$ $0.015 \mathrm{~F} / 10^{6} \mathrm{~h}=15 \mathrm{FIT}$

The resonant inductor contributes to the failure rate. $\lambda_{L}=\lambda_{b} \cdot \pi_{Q} \cdot \pi_{E} \cdot \pi_{C V}=0.00075 \times 1 \times 10 \times 3=$ $0.0225 \mathrm{~F} / 10^{6} \mathrm{~h}=23 \mathrm{FIT}$

Finally, the system-level failure rates for the three cases yield as it follows.

$\Delta \lambda_{1} \cong \Delta \lambda_{2}=\lambda_{M O S F E T, 1}+\lambda_{D I O D E, 1}+\lambda_{L r, 1}+\lambda_{C r, 1}=5,875+$ $540+15+23=6.453$ FIT

$\Delta \lambda_{3}=\lambda_{M O S F E T, 3}+\lambda_{\text {DIODE }, 3}=5,875+1,080=6.955$ FIT

\section{ZCT, using MIL-HDBK-217}

This procedure is very close to the one explained above for the Zero Voltage Transition converter. In the end, the operational junction temperature makes the difference in actual numerical values. Since the negative decrease in capacitance does not have a major impact in lifetime of a properly controlled Zero Current Transition buck converter, details of calculation are not finalized herein.

\section{Summary of results}

Usually, the failure rate for a system is considered constant and this produces a flat lifetime over time. Based on parameter variation and the calculation at each operational temperature, the actual failure rate yields time-varying, that means ageing effects set-in early during the service life. Such time-varying failure rate needs to be used for reliability calculation. However, the compensation of the component ageing with a variable frequency closed-loop controller leads to minimal variation in junction temperature. Some variation is seen for the diode in Table II. The worst-case temperature can be considered in order to avoid a more complicated calculation.

This is studied with a primer in Microsoft Excel able to calculate the effects of constant or time-varying failure rate on reliability probability. Manipulation of component data, peculiar calculation formula and definition of graphs are set for a possible extension to other converters.

Because the constant failure rate $\lambda$ is expressed in FIT in eq. (22-23), the reliability is calculated with:

$R_{c}(t)=e^{\left(-\frac{t}{10^{9}} \cdot \lambda\right)}$
Hence, the probability that the resonant power converter lasts more than 100,000 hours is $52.45 \%$, and $49.88 \%$ for the conventional buck converter.

$R_{\text {reson }}=e^{\left(-\frac{100,000}{10^{9}} \cdot 6,453\right)}=52.45 \%$
$R_{\text {conv }}=e^{\left(-\frac{100,000}{10^{9}} \cdot 6,955\right)}=49.88 \%$

In other words, the probability that the resonant converter lasts more than 20 years is $32.30 \%$, and $29.52 \%$ for the conventional buck converter.

$$
\begin{aligned}
& R_{\text {reson }}=e^{\left(-\frac{175,200}{10^{9}} \cdot 6,453\right)}=32.30 \% \\
& R_{\text {conv }}=e^{\left(-\frac{175,200}{10^{9}} \cdot 6,955\right)}=29.52 \%
\end{aligned}
$$

\section{E. Considering probability of occurrence of peak power}

Usually, the working profile is not known. This means the probability of occurrence of peak power as well as of any other power levels are not known before commissioning of the power supply. The failure rate and reliability are hence calculated for the maximum current, at the peak operational power, considered as potential worst case. This was presented in the previous sections.

Alternatively, when the work profile is actually known and the amount of time spent with operation at a certain power level is known, the calculation can be improved with a profile consideration [35].

Table III illustrates calculation for different current levels or precent of the peak power, for the case of resonant buck converter, built with previous parameters. To simplify the explanation, a poor resolution has been considered at $10 \%$ load power steps, while computer programs can better discretize the profile graph. The column "\% Time" shows how much time is spent around each power level within the known repetitive profile, obviously as an example. A prorated failure rate is calculated by considering effect of junction temperature in (19) and (21). Such failure rate is further weighed with "\% Time" and added into a profile-dependent failure rate. The reliability probability is calculated with (28), and shown in the bottom rightmost corner. This calculation example calculates probability that the resonant power converter lasts more than 100,000 hours.

It is important to note that the outcome (58.97\%) is different from the previously considered worst case of operating always at peak power $(52.45 \%)$. This means the resonant power converter can survive more if operated occasionally at lower power.

TABLE III

\begin{tabular}{|c|c|c|c|c|c|c|c|c|c|c|}
\hline LOAD & CURRENT & $\mathrm{TQ}\left[{ }^{\circ} \mathrm{C}\right]$ & $\pi_{\mathrm{TA}}$ & $\operatorname{TD} 1\left[{ }^{\circ} \mathrm{C}\right]$ & $\pi_{\mathrm{TB}}$ & $\lambda_{1}(\mathrm{FIT})$ & Rreson & \% Time & FIT •\%Time & \\
\hline $100 \%$ & 20.00 & 96 & 3.4 & 43 & 1.5 & 6453 & $52.45 \%$ & 50 & 3227 & \\
\hline $90.0 \%$ & 18.00 & 78 & 2.6 & 40 & 1.4 & 5035 & $60.44 \%$ & 20 & 1007 & \\
\hline $80.0 \%$ & 16.00 & 66 & 2.1 & 38 & 1.3 & 4135 & $66.13 \%$ & 10 & 413 & \\
\hline $70.0 \%$ & 14.00 & 55 & 1.8 & 35 & 1.2 & 3580 & $69.90 \%$ & 10 & 358 & \\
\hline $60.0 \%$ & 12.00 & 46 & 1.5 & 33 & 1.1 & 3026 & $73.89 \%$ & 5 & 151 & \\
\hline \multirow[t]{3}{*}{$50.0 \%$} & 10.00 & 39 & 1.2 & 31 & 1.1 & 2508 & $77.82 \%$ & 5 & 125 & \\
\hline & & & & & & & & $\lambda_{\text {profile }}$ & 5282 & \\
\hline & & & & & & & & Rprofile & $58.97 \%$ & $100,000 \mathrm{~h}$ \\
\hline
\end{tabular}

FAILURE RATE AND RELIABILITY CALCULATED AFTER A PROFILE, USING MIL-HBK-217F 


\section{CONCLUSION}

This paper studies the effect of parameter variation for ZVT or ZCT resonant buck converters in estimation of lifetime and reliability probability. A variation of inductance, capacitance, or both, produces a change in the output voltage of the converter. The resonant buck converter keeps the output voltage constant with a variation of the switching frequency based on a closed loop control. While this is designed in for keeping the voltage constant, it also helps regulating the junction temperature and using a constant failure rate in calculation.

The paper reviews manufacturer and technology data to assess the ageing and post-shock variation of parameters for passive components (capacitors and inductances) to be used within resonant converters. This information is used along a temperature evaluation for an estimation of the lifetime.

A dataset is considered herein as example and a full estimation process for reliability performance is presented based on the MIL-HBK-217F standard. It is concluded that parameter variation must be fully understood and taken into consideration during the design phase. Otherwise, a deterioration of reliability performance yields and the probability of long-time survival can be reduced.

Using reliability standards may be counter-intuitive to a "hands-on" engineer. Data tables from these standards have gathered data from experiment to provide an empirical (or experimental) probability. This is an "estimate" that an event will occur based upon how often the event occurred after collecting data from an experiment in a large number of trials. Using these standard tables for a given converter provides a statistical model based on widely accepted previous experiment. Thus, an empirical probability is achieved for any peculiar case with the expectations this is approaching the theoretical probability. The Law of Large Numbers (called Bernoulli's Theorem) states: "If an experiment is repeated a large number of times, the experimental or empirical probability of a particular outcome approaches a fixed number as the number of repetitions increases. This fixed number is the theoretical probability."

While the resonant power converters are using ceramic capacitors discussed in this paper, reliability of other power converters may be more dependent on electrolytic or polymer capacitors since these cannot benefit from ceramic capacitors. While a calculation based on MIL and FIDES are not unlike the ceramic case, the method based on International Electrotechnical Commission's TR62380 covers better parameters of the new technologies, like polymer capacitors.

Manufacturers usually define lifetime when $50 \%$ of products stop working and use statistically models to identify the reliability probability for this. Reliability probability is calculated with a failure rate, and a proper estimation should consider a time-varying failure rate to include variation due to ageing and post-shock effects.

Based on this study, the following new directions that can advance state of the art knowledge are depicted:
- Using a combination of computer analysis and standards' tables, the lifetime and reliability probability can become an additional criterium (additional to energy savings and cost) for choosing converter solutions.

- Introduction of new technologies for passive components (like polyester capacitor) can better be appreciated with a proper system-level reliability analysis.

- The calculation methods presented herein can be used for real-time reliability evaluation of power converters with irregular profile operation, for better maintenance scheduling or cost reduction.

- Development of computer tools for quick investigation of the design decisions.

\section{ACKNOWLEDGMENT}

The Authors would like to thank, Dr. Hua Jin, President of PowerSim Inc. (the producer of PSIM) for his recommendations in defining the thermal analysis model.

\section{REFERENCES}

[1] M. G. Pecht, F. R. Nash, "Predicting the Reliability of Electronic Equipment," In Proceedings of the IEEE, vol. 82, pp. 992-1004, 1994.

[2] E. Wolfgang, L. Amigues, N. Seliger, G. Lugert, "Building-in Reliability into Power Electronic Systems", ECPE Workshop, pp.246-252, 2008.

[3] H. Calleja, F. Chan, "Reliability: A Neglected Topic in the Power Electronics Curricula", Journal of Power Electronics, Vol. 10, No. 6, November 2010, pp.660-666.

[4] F. Blaabjerg, "Power Electronics and Reliability in Renewable Energy Systems", IEEE IECON Keynote Speaker, Montreal, Canada, 2012.

[5] I. Waseem, M. Pipattanasomporn, S. Rahman, "Reliability benefits of distributed generation as a backup source", IEEE Power \& Energy Society General Meeting, PES '09, pp.1-9, 2009.

[6] Kaplar, R., Marinella, M., Brock R., "Stress Testing of Semiconductor Power semiconductor transistors for PV Inverter Applications at Sandia National Laboratories", Utility-Scale Grid-Tied PV Inverter Reliability Workshop, Sandia Laboratories, 2011.

[7] S. E. De León-Aldaco; H. Calleja; F. Chan; H.R. Jiménez-Grajales, "Effect of the Mission Profile on the Reliability of a Power Converter Aimed at Photovoltaic Applications-A Case Study", IEEE Transactions on Power Electronics, Volume: 28, Issue: 6, Pages: 2998 3007, 2013.

[8] D. Zhou; H.Wang; F. Blaabjerg, "Mission Profile Based System-Level Reliability Analysis of DC/DC Converters for a Backup Power Application", IEEE Transactions on Power Electronics , Volume: 33, Issue: 9, Pages: $8030-8039,2018$.

[9] D. Zhou, G. Zhang and F. Blaabjerg, "Optimal Selection of Power Converter in DFIG Wind Turbine with Enhanced System-Level Reliability," in IEEE Transactions on Industry Applications, vol. 54, no. 4, pp. 3637-3644, July-Aug. 2018.

[10] Dan Butnicu, Dorin O. Neacșu, "A Case Study for Reliability Evaluation of an External Computer Power Supply", Electric Power Components and Systems Journal, Taylor and Francis Group, Volume 47, issue 4-5, pp. 444-455, 2019.

[11] L. F. Costa, G. Buticchi and M. Liserre, "Highly Efficient and Reliable SiC-Based DC-DC Converter for Smart Transformer," in IEEE Transactions on Industrial Electronics, vol. 64, no. 10, pp. 8383-8392, Oct. 2017.

[12] H. Chen, S. Xu and S. Cui, "Reliability Evaluation for Power Converter of SRM on Fault-tolerate Capability and Thermal Stress," accepted for publication (early access) in IEEE Transactions on Industrial Electronics.

[13] Anon., MIL-HDBK-217F = Military Handbook - Reliability Prediction of Electronic Equipment, original copy of 1990, (with subsequent revisions).

[14] Anon., "IEC TR 62380, Reliability data handbook, Universal model for reliability prediction of electronics components, PCBs and equipment", at https://webstore.iec.ch/preview/info_iec62380\%7Bed1.0\%7Den.pdf; 2004.

[15] Stefanie Bourbouse, "Introduction to the FIDES method in the frame of its application to Space", 
at https://nepp.nasa.gov/workshops/etw2019/talks/0619WED/1630\%20\%20Bourbouse\%20-\%20NEPP_2019_FIDES.pdf

[16] Alena Pietrikova, Magdaléna Bujalobokova, Juraj Bansky, "Reliability Evaluation Procedure of Thick Film Inductors Manufactured by Various Techniques", Acta Electrotechnica et Informatica, No. 3, Vol. 6, 2006, Kosice, Slovak Republic, pp.1-5.

[17] J.Kindmark and F. Rosen, "Powder Material for Inductor Cores, Evaluation of MPP, Sendust and High flux core characteristics", Master of Science Thesis, Chalmers University of Technology, Geoteborg, Sweden, 2013.

[18] Anon., "Notes on Thermal Aging in Inductor Cores", Coilcraft Corporation, Document 1192-1 Revised 05/14/2014.

[19] E. Overton, A. N. Hammoud , E. D. Baumann and I. T. Myers, "Thermal Aging Effects on the Electrical Properties of Film and Ceramic Capacitors", 1993 Electrical/Electronics Insulation Conference, 1993.

[20] Anon., Application note AN0006, "Capacitance Ageing of Ceramic Capacitors, Explanation of the natural ageing process resulting in logarithmic loss of Capacitance", Technical report Knowles, 2006.

[21] Anon., "Ceramic capacitor aging made simple", Johanson Dielectrics Inc, Technical report, 2012.

[22] Anon., "Circuit's designer notebook - Dielectric ageing phenomena", available at https://atceramics.com/userFiles/uploads/pdfs/dielectric_aging.pdf

[23] J. Huang, L. Mei, and C. Gao, "Life Prediction of Tantalum Capacitor Based on Gray Theory Optimization Model,", IEEE Int'l Conf. on Quality and Reliability, Sept. 2011, pp. 166-171

[24] A. Gupta, O.P. Yadav, D. DeVoto, J. Major, "A Review of Degradation Behavior and Modeling of Capacitors", National Renewable Energy Laboratory NREL/CP-5400-71386, Internet report, 2018, https://www.nrel.gov/docs/fy19osti/71386.pdf.

[25] M. Makdessi, A. Sari, P. Venet, P. Bevilacqua and C. Joubert, "Accelerated Ageing of Metallized Film Capacitors Under High Ripple Currents Combined with a DC Voltage," in IEEE Transactions on Power Electronics, vol. 30, no. 5, pp. 2435-2444, May 2015.

[26] J. Marcos-Acevedo, E. Soto-Campos, S. Fernandez-Gomez, "Analysis of the degradation of the static characteristics of aged discrete and monolitic components," 9th International Conference on Reliability, Maintainability and Safety (ICRMS), Guiyang, June 2011.

[27] He Huang, Alexandre Boyer, Sonia Ben Dhia, "Passive device degradation models for a electromagnetic emission robustness study of a buck DC-DC converter”, EMC Europe 2015, August 2015, Dresden, Germany, pp.1-6.

[28] H. Valipour, M. Fotuhi Firouzabad, G. Rezazadeh and M. R. Zolghadri, "Reliability comparison of two industrial AC/DC converters with resonant and non-resonant topologies," The 6th Power Electronics, Drive Systems \& Technologies Conference (PEDSTC2015), Tehran, 2015 , pp. $430-435$

[29] O. Knecht, D. Bortis, J.W. Kolar, ,ZVS Modulation Scheme for Reduced Complexity Clamp-Switch TCM DC-DC Boost Converter", IEEE Transactions on Power Electronics, vol. 33, no. 5, May 2018, pp.42044216, 2018

[30] D.O. Neacsu, "Switching Power Converters", CRC Press, 2013.

[31] C. Oeder, M. Barwig and T. Duerbaum, "Estimation of power semiconductor transistor losses in resonant converters based on datasheet information," 2016 18th European Conference on Power Electronics and Applications (EPE'16 ECCE Europe), Karlsruhe, 2016, pp. 1-9. doi: 10.1109/EPE.2016.7695275.

[32] D.O. Neacșu, Dan Butnicu, ,On the Reliability Performance Degradation due to Misalignment of Zero Voltage Transition Resonant Converter Operation", The Bulletin of IPI, Electrotechnic-Energetic-Electronics Section, Romania, Vol. 65 (69), nr.2, 2019, pp. 69-87.

[33] Anon., PSIM webpage, October 2019.

[34] D. Butnicu, "A Reliability Comparison between Disrupting eGaN-FET and Cutting Edge Silicon MOSFET Devices in POL Buck Converters", 2019 International Symposium on Signals, Circuits and Systems, ISSCS, Iasi, July 2019

[35] Allan Webber, "Calculating FIT for a Mission Profile", Texas Instruments Application Report, SPRABY3-March 2015.

\section{APPENDIX Demonstration of equation 7}

Calculation and notations follow Fig. 2.

When the power semiconductor transistor $Q$ is turned-off, the current diverges from power semiconductor transistor into the resonant capacitor, and its voltage increases linearly:
$v_{C_{r}}(t)=\frac{I_{L}}{C_{r}} \cdot t$

The buck diode $D$ sees a cathode-anode voltage of:

$v_{D}(t)=E-\frac{I_{L}}{C_{r}} \cdot t$

A positive voltage turns-on the output diode $D$ and the load current gets re-routed from resonant capacitor to the buck diode. The time interval in between the turn-off of the transistor and before the diode turns-on can be calculated with $t_{1}=\frac{E}{I_{L}} \cdot C_{r}$

For unified design, the components $\left(L_{r}\right.$ and $\left.C_{r}\right)$ added to the circuit for the resonant swing, can be characterized collectively with a resonant frequency $f_{r}$ and a characteristic impedance $Z_{r}$.

$f_{r}=\frac{1}{T_{r}}=\frac{1}{2 \cdot \pi \cdot \sqrt{L_{r} \cdot C_{r}}}$

$Z_{r}=\sqrt{\frac{L_{r}}{C_{r}}}$

This can be used along (A3) to produce (A6).

$t_{1}=\frac{E}{I_{L}} \cdot C_{r}=\frac{E}{I_{L}} \cdot \frac{1}{\omega_{r} \cdot Z_{r}}$

This time interval has to be smaller than the power semiconductor transistor period of the buck converter so that the average of the voltage pulses and the harmonic content are not changed. Both components, $L_{r}$ and $C_{r}$, have to be selected to match this design rule.

While the load current passes through the buck diode and the power semiconductor transistor remains in the off state, the input voltage $E$ equals the sum of voltage drop across $L_{r}$ and $C_{r}$.

$L_{r} \cdot C_{r} \cdot \frac{d^{2} v_{C_{r}}(t)}{d t^{2}}+v_{C_{r}}(t)=E$

As explained, the buck diode turned-on when the voltage across the resonant capacitor equaled $E$. During the conduction of the buck diode, the voltage across the resonant capacitor $C_{r}$ increases from $E$ to a peak value, then decreases to zero, after a sinusoidal law:

$v_{C_{r}}(t)=E+Z_{r} \cdot I_{L} \cdot \sin \left[\omega_{r} \cdot\left(t-t_{1}\right)\right]$

The peak of the capacitor voltage can also be considered as the maximum voltage drop across the power semiconductor transistor, that is:

$v_{C_{r}(\max )}=E+Z_{r} \cdot I_{L}$

The moment of time when voltage across $C_{r}$ capacitor reaches zero yields:

$t_{2}=t_{1}+\frac{1}{\omega_{r}} \cdot\left[\pi+\arcsin \left(\frac{E}{z_{r} \cdot I_{L}}\right)\right]$

This time interval is the minimum duration of the off-state for the main power semiconductor transistor. At this moment $t_{2}$, the current through $L_{r}$ and $C_{r}$ yields:

$i_{C r}\left(t_{2}\right)=i_{L r}\left(t_{2}\right)=-I_{L} \cdot \sqrt{\left[1-\left[\frac{E}{z_{r} \cdot I_{L}}\right]^{2}\right]}$

The buck diode is seeing the sum of the current through the resonant circuit and the load current.

$i_{D}\left(t_{2}\right)=I_{L}+I_{L} \cdot \sqrt{\left[1-\left[\frac{E}{z_{r^{\prime}} I_{L}}\right]^{2}\right]}$

After $t_{2}$, the voltage across the resonant capacitor $C_{r}$ tends to negative values. This turns-on the anti-parallel diode which re-routes the circulation of the current until the resonant circuit 
energy is discharged. Since both diodes are in conduction, the voltage across the $L_{r}$ is maintained constant and equal to converter's input voltage. A constant voltage drop across $L_{r}$ means a linear variation for the current:

$i_{Q}(t)=i_{L r}(t)=\left[-I_{L} \sqrt{\left[1-\left[\frac{E}{z_{r} \cdot I_{L}}\right]^{2}\right]}\right]+\frac{E}{L_{r}} \cdot\left(t-t_{2}\right)$

The current through the buck diode $D$ yields as the algebraic sum of the current through the resonant circuit and the load current.

$i_{D}(t)=I_{L} \cdot\left[1+\sqrt{\left[1-\left[\frac{E}{z_{r} \cdot I_{L}}\right]^{2}\right]}\right]+\frac{E}{L_{r}} \cdot\left(t-t_{2}\right)$

The main power semiconductor transistor should not be turned-on before resonant circuit energy is discharged. The moment of time $t_{3}$ when the current through the resonant inductor and the anti-parallel diode reaches zero yields:

$t_{3}=t_{2}+\frac{1}{\omega_{r}} \cdot \frac{z_{r} \cdot I_{L}}{E} \cdot \sqrt{\left[1-\left[\frac{E}{z_{r} \cdot I_{L}}\right]^{2}\right]}$

A correct design implies the off-state of the power semiconductor transistor needs to match the time interval between $t_{1}$ and $t_{3}$. A turn-on command produces a current circulation through the resonant inductor $L_{r}$ and the output diode. Because the output diode is still in conduction, the voltage across the resonant inductor $L_{r}$ equals the input voltage $E$. The current will maintain the linear variation from zero to the load current $I_{L \text {. }}$

$i_{D}(t)=I_{L} \cdot\left[1+\sqrt{\left[1-\left[\frac{E}{z_{r} \cdot I_{L}}\right]^{2}\right]}\right]+\frac{E}{L_{r}} \cdot\left(t-t_{2}\right)$

The current through the buck diode will eventually reach zero at a moment of time $t_{4}$.

$t_{4}=t_{3}+\frac{1}{\omega_{r}} \cdot \frac{z_{r} \cdot I_{L}}{E}=t_{2}+\frac{1}{\omega_{r}} \cdot \frac{z_{r} \cdot I_{L}}{E} \cdot\left[1+\sqrt{\left[1-\left[\frac{E}{z_{r} \cdot I_{L}}\right]^{2}\right]}\right]$

After the moment $t_{4}$, the load current passes through the power semiconductor transistor and the resonant inductor $L_{r}$. The power semiconductor transistor can be turned-off at any moment after $t_{4}$, and the entire operation is repeated cyclically.

Within a conventional, hard-switched buck converter, the moments when the power semiconductor transistor is switched between on and off states are defined based on the duty cycle required to produce a certain output voltage. For a resonant converter, additional limits for operation are imposed to maintain either zero-voltage or zero-current capability. Such limits are governed herein by the instants $t_{2}$ and $t_{4}$ as calculated above. Their values are dependent on $L_{r}$ and $C_{r}$ as well as on the load current and converter's input voltage.

Passive components are considered with constant parameters in conventional design process. In most design cases, the load current becomes the only variable parameter during the operation of the power stage. The ZVT resonant circuit works appropriately when the following constraint is respected.

$Z_{r} \cdot I_{L} \geq E$

Equations (A5) and (A18) are used within a converter design able to guarantee a resonant operation at any current above $40 \%$ of the maximum load current.
$\sqrt{\frac{L_{r}}{C_{r}}} \cdot 0.4 \cdot I_{L} \geq E$

This design example leads to the nominal values.

$\frac{L_{r}}{C_{r}} \geq 225 \rightarrow L_{r}=5 \mu \mathrm{H} ; C_{r}=22 n F$

Observing waveforms in Fig. 2 allows calculation of the output voltage.

$V_{\text {out }}=E \cdot\left[1-\frac{t_{\text {zero }}}{T}\right]+E \cdot \frac{1}{2} \cdot \frac{E}{I_{L}} \cdot \frac{1}{\omega_{r} \cdot Z_{r}}$

where

$t_{\text {zero }}=t_{4}-t_{0}=\frac{E}{I_{L}} \cdot \frac{1}{\omega_{r} \cdot z_{r}}+\frac{1}{\omega_{r}} \cdot\left[\pi+\arcsin \left(\frac{E}{z_{r} \cdot I_{L}}\right)\right]+\frac{1}{\omega_{r}}$.

$\left.\frac{z_{r} \cdot I_{L}}{E} \cdot\left[1+\sqrt{\left[1-\left[\frac{E}{z_{r} \cdot I_{L}}\right]^{2}\right.}\right]\right]$

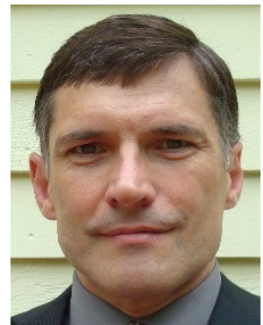

Dorin O. Neacşu (M'95-SM'00) has received the $\mathrm{MSc}$ and $\mathrm{PhD}$ degrees in Electronics from the Technical University of Iasi, Iasi, Romania, in 1988 and 1994, respectively, and a MSc degree in Engineering Management from Gordon Institute for Leadership, Tufts University, in 2005.

Dorin has been involved with TAGCM-SUT Iasi, Romania, from 1988 to 1990 , and with the faculty at Department of Electronics, Technical University of Iasi, Romania, between 1990 and 1999. Following 1999, he was involved with the U.S. industry as an engineer, consultant, product manager, and project manager, and with U.S. academic activities. Since 2012, Dorin is an Associate Professor with Technical University of Iasi and was a Visiting Associate Professor with Northeastern University, Boston, MA, USA.

Professor Dorin O. Neacşu has organized 9 professional education seminars (tutorials) at IEEE conferences. He has published "Switching Power Converters - Medium and High Power", "Telecom Power Systems", "Automotive Power Systems", all available at CRC Press/Taylor and Francis. He has received the 2015 "Constantin Budeanu" award of the Romanian Academy of Sciences, and the 2018 "Ad Astra" award from Romanian Researchers Association. Dorin is an Associate Editor of IEEE Transactions on Power Electronics, Associate Editor of IEEE IES Magazine, Reviewer for IEEE Transactions and Conferences, Member of IEEE committees.

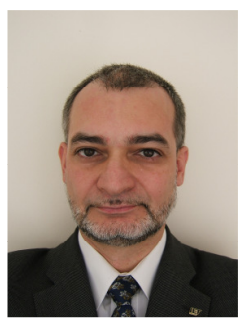

Marcian N. Cirstea (M'97-SM'04) received a degree in electrical engineering in 1990 from Transilvania University of Brasov, Romania, and a Ph.D (1996) from Nottingham Trent University, UK. He is Professor (since 2007) and Head of School of Computing and Information Science at Anglia Ruskin University, Cambridge, UK, after having worked previously for De Montfort University, UK. His research focuses on the use of computer aided design tools and methods applied to digital systems modelling and rapid prototyping using VHDL and FPGAs, with particular interest in artificial intelligence.

With 30 years of professional experience, he has published one research monograph, one text-book and 150 peer-reviewed papers in these topics and has delivered a number of international tutorials /presentations on electronic systems modeling and FPGA controller Prototyping.

Professor Cirstea is founder and past Chair of the 'Electronic Systems on Chip' Technical Committee of IEEE Industrial Electronics Society, Fellow of the IET and Chartered Engineer (CEng). He is Associate Editor for IEEE Transactions on Industrial Informatics, was Vice-President for Membership Activities in the IEEE Industrial Electronics Society (2013-16) and has chaired a range of IEEE conferences. He has coordinated an European FP6 renewable energy project consortium. In January 2016, his achievements were celebrated through the award of the Doctor Honoris Causa title by Transilvania University of Brasov, Romania. 


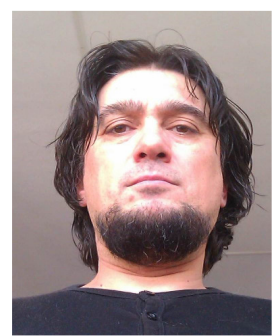

Dan Butnicu (M'00) received the BE and MSc degree in 1988, from the Department of Electrical Engineering of the Politechnic Institute "Ghe. Asachi" Iasi, Romania, and the $\mathrm{PhD}$ degree in 2019 , from the Technical University of Iasi, Romania. He has authored /coauthored several research papers in international journals and conferences, including IEEE Transactions. From 1988 to 1991, Dan has been with Prahova - Military fighting vehicles plant, Romania, as an intern engineer. Since 1991 to present, he was with Basics of Electronics Department at Technical University of Iasi, Romania. His research interests include power electronics, ac-dc and $\mathrm{dc}-\mathrm{dc}$ power converters, resonant converters, reliability, power quality, harmonics, eGaN-FET transistor-based converters, polymer capacitors and MLCCs. Dr. Butnicu served as a Reviewer for TPEL journal, EPC\&Systems Journal, and various international conferences of the IEEE. He is an IES and PELS - IEEE member. 